\title{
Progress Achieved in Gandhinagar District of Gujarat State for Elimination of Malaria, 2007 to 2015-A Case Study
}

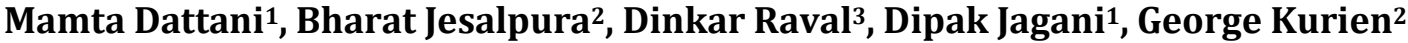 \\ ${ }^{1}$ District Panchayat, Gandhinagar, India \\ ${ }^{2}$ National Vector Borne Disease Control Programme, Gandhinagar, India \\ ${ }^{3}$ Epidemic, Gandhinagar, India \\ Email:mldattani@yahoo.co.in
}

How to cite this paper: Dattani, M., Jesalpura, B., Raval, D., Jagani, D. and Kurien, G. (2017) Progress Achieved in Gandhinagar District of Gujarat State for Elimination of Malaria, 2007 to 2015-A Case Study. Open Journal of Epidemiology, 7, 273-278.

https://doi.org/10.4236/ojepi.2017.73021

Received: December 5, 2016

Accepted: August 21, 2017

Published: August 24, 2017

Copyright $\odot 2017$ by authors and Scientific Research Publishing Inc. This work is licensed under the Creative Commons Attribution International License (CC BY 4.0).

http://creativecommons.org/licenses/by/4.0/

\begin{abstract}
Background: Government of India has lunched the frame work for eliminating malaria from the country by 2030 [1] [2]. But progressive States like Gujarat has to achieve the target by 2024. The first step in this direction is to bring down the Annual Parasitic Incidence less than 1.0. Under National Vector Borne Disease Control Programme (NVBDCP) various activities for Vector control coupled with complete treatment to confirm malaria cases within 24 hours were given more focus and implemented diligently and effectively. Aim: To evaluate the progress of the efforts being undertaken for malaria elimination in Gandhinagar district. Design: Impact of malaria control efforts in Gandhinagar district covering all areas were studied in detail. Setting: Malaria prone villages of Gandhinagar district where preventive actions were undertaken in an integrated manner during the period of 2005 to 2015. Exploratory: Data pertaining to rural and urban areas of the district covering all PHCs, UHCs and Towns were analyzed and interpreted. Outcome: Reduction in malaria incidence and scaling up of non chemical methods for control of malaria. Analysis: Percentage and proportions. Results: Area specific approach adopted in rural areas of Gandhinagar district by putting more emphasis on good surveillance, ensuring complete treatment to malaria cases within 24 hours and effective strategy for vector control mainly non chemical methods resulted in reducing Annual Parasitic Incidence (API) from 1.96 in 2005 to 0.17 in 2015 in Gandhinagar district. 226 villages (74.83\%) out of 302 in the district are malaria free and only 9 villages are having API $>1.0$. The district aims to achieve malaria elimination in the next five years. Conclusion: Gandhinagar district has made rapid stride towards malaria elimination in a
\end{abstract}


cost effective manner by utilizing the available resources. The strategies adopted by the district can be replicated by other districts and States to achieve the goal of malaria elimination.

\section{Keywords}

Annual Parasitic Incidence, Surveillance

\section{Introduction}

Government of India has lunched the frame work for eliminating malaria from the country by 2030 in a phased manner. But progressive States like Gujarat has to achieve the target by 2024 or even before that. The first step in this direction is to bring down the Annual Parasitic Incidence less than 1.0. Under National Vector Borne Disease Control Programme various activities for Vector control coupled with good surveillance ensuring complete treatment to confirm malaria cases within 24 hours were given more focus and implemented diligently and effectively. Gandhinagar district could effectively control the incidence of malaria during the last 10 years and is in a better position to sustain the achievements and make the district free from malaria. This study was undertaken with an aim to evaluate the progress of the efforts being undertaken for malaria elimination in Gandhinagar district, with an aim to further strengthen the efforts to achieve the ultimate goal of "Malaria Free Gandhinagar district".

\section{Methods and Results}

Gandhinagar district comprising of 4 talukas, 302 villages with a total population of 12.02 lakhs. Do have good health infrastructure. There are 171 Sub Centers, 26 PHCs, 4 towns, 9 CHCs and 1 Hospitals. The 914 ASHAs deployed under National Health Mission since 2009 has improved surveillance for malaria. Taluka wise details are given in the Table 1.

Though the district implemented malaria control activities within the framework of the strategies formulated by Government of India, the activities under various strategies were fine tuned to get maximum impact. One of the important activity in which more attention was given was surveillance as can be seen from the Graph $1 \&$ Graph 2. The red line in the graph denotes the expected Annual

Table 1. Demographic details and health infrastructure in Gandhinagar district.

\begin{tabular}{cccccccc}
\hline Taluka & Population & Villages & PHCs & CHCs & Towns & Hospitals & ASHAs \\
\hline Gandhinagar & 345,817 & 73 & 8 & 3 & 1 & 1 & 286 \\
Dehgam & 278,935 & 93 & 7 & 2 & 1 & & 225 \\
Mansa & 233,249 & 66 & 5 & 1 & 1 & 1 & 177 \\
Kalol & 375,011 & 70 & 6 & 3 & 1 & & 226 \\
& $1,233,012$ & 302 & 26 & 9 & 4 & 2 & 914 \\
\hline
\end{tabular}

PHC: Primary Health Centre, CHC: Community Health Centre, ASHA: Accredited Social Health Activist. 


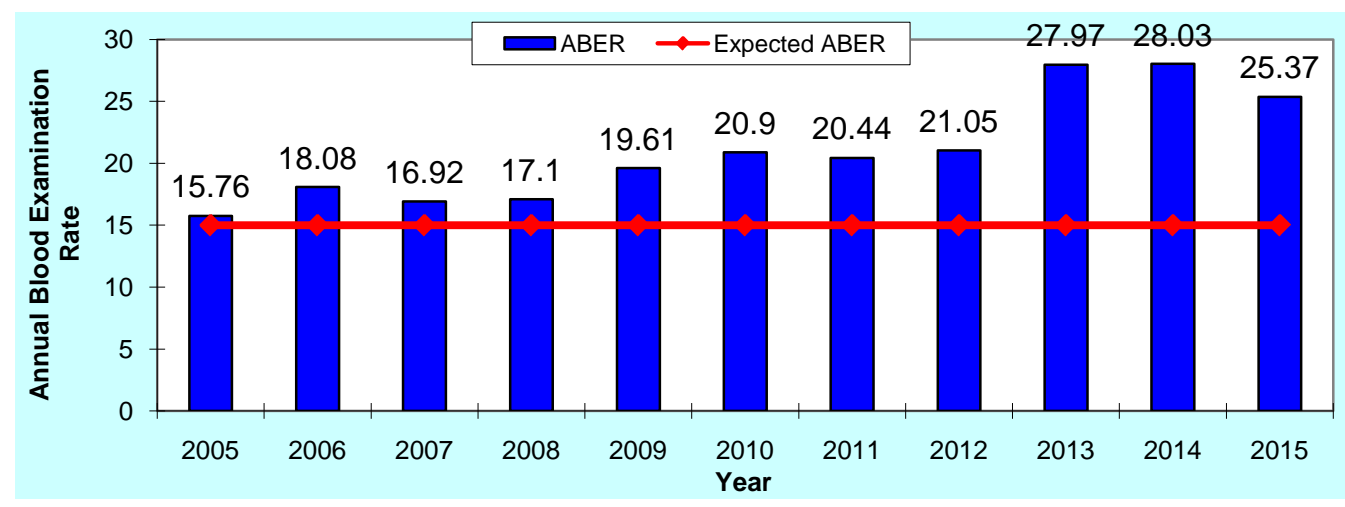

Graph 1. Year wise Annual Blood Examination Rate from 2005-2015.

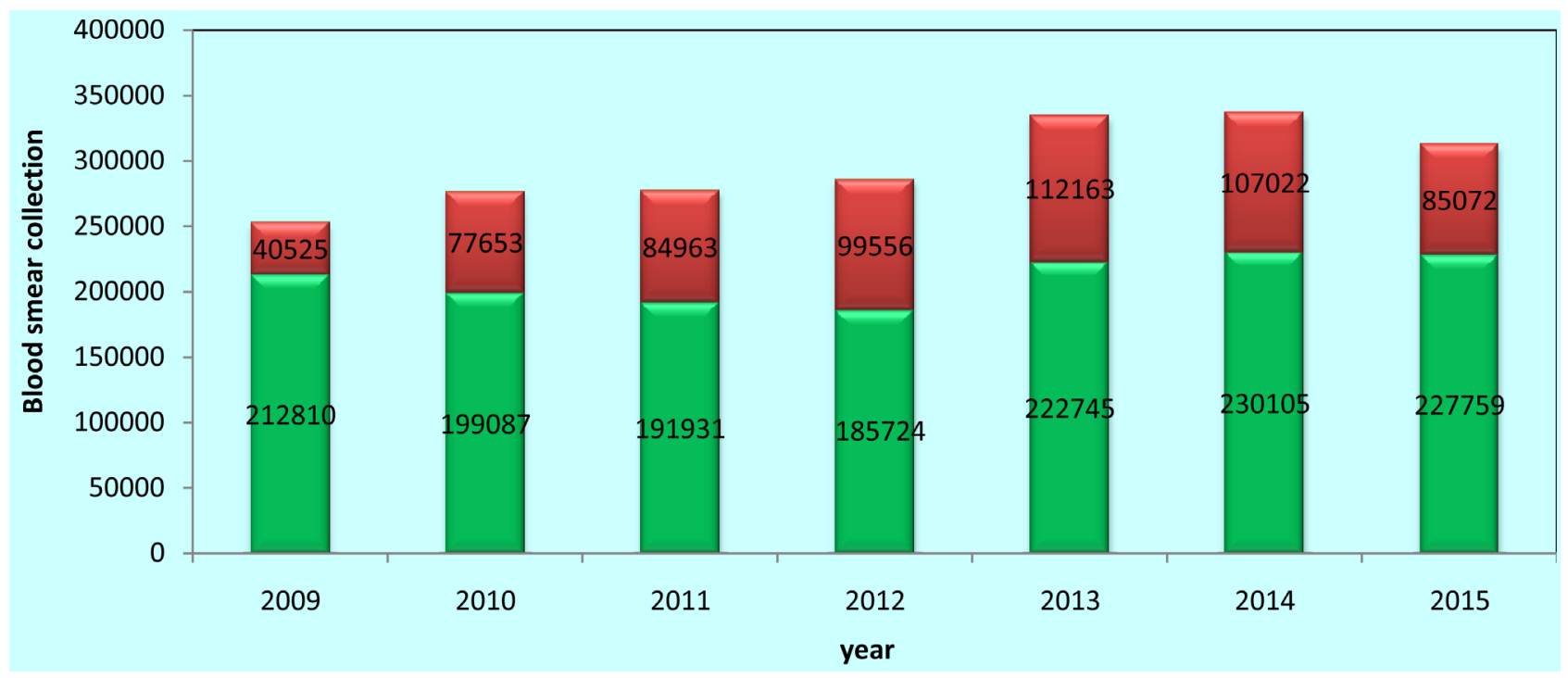

Graph 2. Year wise Blood Smear Collection and contribution of ASHA from 2009-2015.

Blood Examination rate (ABER) and in all the years it has been achieved.

Under parasite elimination and disease management several innovations were introduced viz. ensuring treatment of malaria cases within 24 to 72 hours (208/237 malaria cases in 2014 and 201/205 malaria cases in 2015) tracking of all malaria cases (100\%) and timely referral of severe patients from the periphery. Use of RDTs by ASHAs too helped ensuring early and complete treatment. Case fatality was zero in the district. 102 test done by ASHA and 1 positive case found in RDT [3].

Similarly under Integrated Vector Management all the vector control options were implemented considering the prevailing situation and feasibility. During the period of 2005 to 2015 dependence on Indoor Residual Spray was gradually reduced as shown in the following Table 2 [4] [5].

Other environmental friendly measures such as biological control, treatment of mosquito nets owned by the community was also taken up quite effectively and the work done under these activities are given in the Table $3 \&$ Table 4 [7].

Effective supervision and monitoring played a vital role in achieving the desired success. This activity was diligently carried out at all levels i.e. PHC, Taluka 
M. Dattani et al.

Table 2. Year wise information of Indoor Residual Spray from 2006-2016.

\begin{tabular}{ccccccccccccc}
\hline \multirow{2}{*}{ Year } & \multicolumn{2}{c}{ Total in the district } & \multicolumn{2}{c}{ Eligible for spray } & \multicolumn{3}{c}{ Targeted for spray } & \multicolumn{3}{c}{ Covered under Spray } & \multirow{2}{*}{ \% Room } \\
\cline { 2 - 9 } & Villages & Pop & Villages & Pop & Pop & Houses & Rooms & Pop & Houses & Rooms & Coverage \\
\hline 2006 & 298 & $1,191,830$ & 22 & 54,041 & 54,041 & 10,808 & 28,642 & 54,041 & 9395 & 24,897 & 87 \\
2007 & 298 & $1,225,877$ & 23 & 57,685 & 57,685 & 11,537 & 30,573 & 57,685 & 9986 & 28,551 & 86 \\
2008 & 298 & $1,260,582$ & 16 & 50,250 & 50,250 & 10,050 & 26,633 & 50,250 & 8056 & 21,514 & 81 \\
2009 & 298 & $1,292,093$ & 1 & 1435 & 1435 & 287 & 761 & 1435 & 255 & 665 & 87.4 \\
2010 & 298 & $1,324,412$ & 2 & 7810 & 7810 & 1564 & 4145 & 7810 & 1357 & 3614 & 87.2 \\
2011 & 298 & $1,354,938$ & 2 & 5967 & 5967 & 1193 & 3162 & 5967 & 1034 & 2740 & 86.6 \\
2012 & 298 & $1,354,938$ & 2 & 5810 & 5810 & 1162 & 3079 & 5810 & 1037 & 2747 & 89.1 \\
2013 & 302 & $1,192,517$ & 5 & 18,043 & 18,043 & 3609 & 9563 & 18,043 & 3220 & 8482 & 88.7 \\
2014 & 302 & $1,199,478$ & 3 & 8507 & 8507 & 1701 & 4509 & 8507 & 1498 & 3877 & 86 \\
2015 & 302 & $1,233,012$ & 2 & 495 & 495 & 106 & 424 & 495 & 98 & 390 & 91.9 \\
2016 & 302 & $1,225,731$ & 0 & 0 & & & & NO SPRAY & & \\
\hline
\end{tabular}

Table 3. Year wise information of Biological control from 2006-2015.

\begin{tabular}{lc}
\hline \multicolumn{2}{c}{ Biological control } \\
\hline Year & Number of places where larvivorous fishes introduced \\
\hline 2006 & 260 \\
2007 & 792 \\
2008 & 1040 \\
2009 & 511 \\
2010 & 837 \\
2011 & 625 \\
2012 & 629 \\
2013 & 450 \\
2014 & 1340 \\
2015 & 2700 \\
\hline
\end{tabular}

Table 4. Year wise information of Insecticide Treated Mosquito Nets from 2006-2015.

\begin{tabular}{lc}
\hline \multicolumn{2}{c}{ Mosquito nets } \\
\hline Year & Number of Mosquito nets treated with insecticides \\
\hline 2006 & 7623 \\
2007 & 19,969 \\
2008 & 15,820 \\
2009 & 9461 \\
2010 & 22,550 \\
2011 & 24,010 \\
2012 & 15,271 \\
2013 & 917 \\
2014 & 11,537 \\
2015 & 11,501 \\
\hline
\end{tabular}


and District level. Prescribed check lists were used for effective supervision. Treatment cards were maintained to verify completion of treatment given to malaria cases.

\section{Conclusions}

The study revealed that the integrated approach adopted in the district has brought down the malaria incidence to a very low level as Annual Parasitic Incidence has declined in 2015 as compared to 2005 as shown in the Graph 3 ([6] [7]).

Majority of the villages in the district could be made malaria free as can be seen from the GIS Map 1.

This achievement is of much significance as the surveillance for malaria has remained very good all these years. The outcome of the efforts made in Gandhinagar district is quite encouraging when concerted efforts have been put in and milestones have fixed for elimination of malaria. The key for elimination from the context of this study is to establish a robust surveillance mechanism (concept

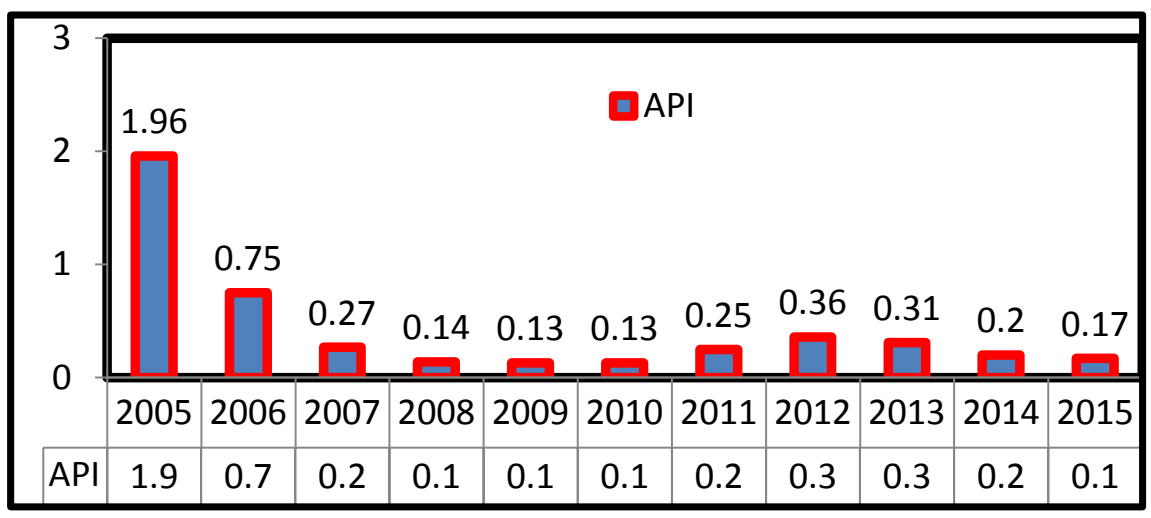

Graph 3. Year wise Annual Parasite Incidence from 2005-2015.
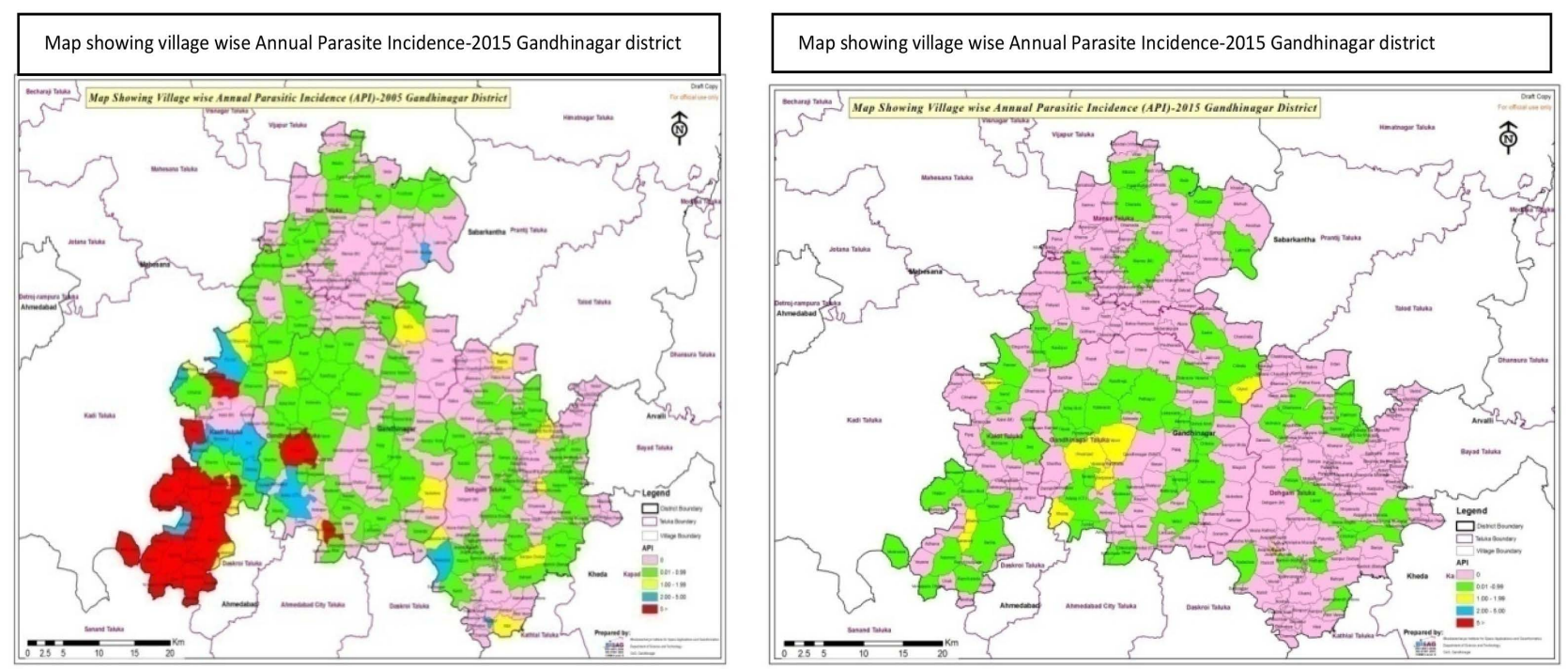

Map 1. Left, Map showing village wise Annual Parasite Incidence-2005 Gandhinagar district; Right, Map showing village wise Annual Parasite Incidence-2015 Gandhinagar district. 
of T3: Test, Treat and Track) with equal emphasis for vector control and monitoring activities on a regular basis.

\section{Acknowledgements}

The authors acknowledge the support received from the District administration particularly the District Development Officer, Chief District Health Officer and the team of District Malaria Office. The contribution of the medical and paramedical personnel of Gandhinagar district is also noteworthy. These field level functionaries contributed a lot by their timely and effective actions. The motivation and guidance received from State Programme Officer and team is also acknowledged.

\section{References}

[1] National Frame Work for Malaria Elimination, NVBDCP Delhi, 2016.

[2] Operational Manual for Malaria Elimination, NVBDCP, Delhi, 2016.

[3] Dattani, M., et al. (2014) Malaria Treatment, Compliance \& Cure in Gandhinagar District of Gujarat. Health, 6, 6-9. https://doi.org/10.4236/health.2014.61002

[4] Sustaining Achievement under Malaria Control in Gandhinagar District of Gujarat. Bioscience Guadian, 2.

[5] Operational Manual for Integrated Vector Management, NVBDCP Delhi, 2016.

[6] Dattani, et al. (2009) Impact of IRS with Synthetic Pyrethroid for Control of Malaria in Gandhinagar District of Gujarat. Indian Journal of Community Medicine, 34.

[7] WHO Guideline for Control of Malaria in Low Endemic Countries.

\section{Submit or recommend next manuscript to SCIRP and we will provide best service for you:}

Accepting pre-submission inquiries through Email, Facebook, LinkedIn, Twitter, etc. A wide selection of journals (inclusive of 9 subjects, more than 200 journals)

Providing 24-hour high-quality service

User-friendly online submission system

Fair and swift peer-review system

Efficient typesetting and proofreading procedure

Display of the result of downloads and visits, as well as the number of cited articles

Maximum dissemination of your research work

Submit your manuscript at: http://papersubmission.scirp.org/

Or contact ojepi@scirp.org 